\title{
Facilitating innovation in European research area through pre-competitive EU-funded COST Actions
}

\author{
Ruslan Rakhmatullin ${ }^{1 *}$ and Louis Brennan ${ }^{2}$
}

\author{
* Correspondence: \\ ruslan.rakhmatullin@ec.europa.eu \\ ${ }^{1}$ European Commission, Joint \\ Research Centre (JRC), Institute of \\ Prospective Technological Studies \\ (IPTS), Seville, Spain \\ Full list of author information is \\ available at the end of the article
}

\begin{abstract}
The European Union (EU) Heads of States regularly confirm that knowledge and innovation are critical to Europe's growth and agreed to make the EU the most competitive knowledge-driven economy. The EU's ability to facilitate innovation by strengthening its research capacities is central to achieving this goal. Some EU initiatives under this innovation policy integrate research capacities already existing in individual states through pan-European participation in collaborative projects in science and technology. The EU is financing a number of formal pre-competitive networking programs aiming at a better deployment of existing national research capacities via their inclusion in joint research initiatives. Although there is a general consensus that increasing levels of collaboration amongst researchers produce better results, the issue of research networking and of related research outcomes continues to generate debate with a wide variety of views on what roles such programs play and their general implications for research and scientific performance. As the EU Framework Programme 7 is coming to its end, this paper explores whether such formal networking programs contribute to facilitating innovation in the European Research Area by enabling Science and Technology participants to achieve anticipated research outcomes from their involvement in such programs.
\end{abstract}

Keywords: Innovation; Collaboration; COST Action; Science and technology; Framework Programme 7; Pre-competitive; Formal networking programs

\section{Background}

Although there is a general consensus that increasing levels of collaboration amongst researchers produce better results (Rigby and Edler 2005), the issue of research networking and of related research outcomes continues to generate a debate with a wide variety of views on what roles such programs play and their general implications for research and scientific performance. Lately, formal research networks are considered as the answer to a range of challenges. Research suggests that networking efforts can result in formal and informal networks which in turn are parts of social innovation and learning as their participants often seek collaboration with others in order to facilitate exchange of information, knowledge and experiences and to build collaborations to implement new ways of thinking and working (Alders et al. 1993).

In 2000, the European Union (EU) committed to working towards the Lisbon goals becoming the most competitive knowledge-driven economy in the world. Achieving these Lisbon goals depends on the EU's ability to facilitate innovation by strengthening 
its research capacities. Some of the practical initiatives under the EU's innovation policy integrate research capacities already existing in individual states through pan-European participation in collaborative projects in science and technology. One of such EUfunded intergovernmental frameworks specifically aiming at supporting collaboration and cooperation in the field of science and technology is European Cooperation in Science and Technology (COST).

Professor Francesco Fedi, the President of the COST Committee of Senior Officials, recently stressed the role of COST in contributing to the Lisbon objectives (COST 2007). He argues that it is due to the specific features of COST which ensured its achievements throughout the last 37 years: 'its intergovernmental nature, its bottom-up approach, its flexibility, its position as an open network among researchers and as an exploratorium of new ideas in the most advanced frontiers of science; its complementary role with respect to the EC Framework Programmes; its role towards the new Member States of the European Union, the European neighbouring countries and, in general, towards the rest of the world' (COST 2007, p.1).

Despite the fact that the COST framework has been around for more than 30 years, there is only limited evidence in the literature to support the role of such formal networking research activities in contributing to the Lisbon objectives. In fact, while there is a general consensus that increasing levels of collaboration amongst researchers produce better results, the issue of research networking and of related research outcomes continues to generate debate with a wide variety of views on what roles such programs play and their general implications for research and scientific performance.

One of the questions is whether such formal networking research (FNR) programs are capable of achieving applied science and technology (S\&T) results. This paper is a preliminary attempt to examine some of the S\&T outputs attainable in formal networking research projects, taking the case of COST Actions as an example of such funded projects. The extent to which some of the S\&T outputs are achieved in FNR projects is explored by utilizing self-reported data collected in a survey of participants with experience of such networking projects. Based on the empirical findings, the potentials of FNR projects in achieving certain applied research outputs are then discussed. The implications for future research are also considered.

\section{Results and discussion}

\section{Defragmentation of European research}

The European Research Area (ERA) was formally established by the EU Council's resolution in June 2000. Establishing the ERA meant creating a common European zone with a specific emphasis on knowledge creation and sharing, innovation and the optimization of human capital. During the Lisbon Summit in 2000, the EU Heads of States and Governments confirmed that knowledge and innovation are vital to Europe's growth and agreed to make the EU the most competitive knowledge-driven economy. The EU's ability to facilitate innovation by strengthening its research capacities is central to achieving these Lisbon goals.

Some of the ERA objectives are central to the topic of this research paper: (1) provision of coordinated support to researchers in order to contribute to world-class S\&T excellence in Europe relying on cooperation and coordination; and (2) promotion of S\&T capacity building across Europe so that the entire ERA could build on their strengths while 
gaining and maintaining access to complementary specialized knowledge and S\&T capacities in the rest of Europe (EU Council 2009). A wide range of research parties from a number of different countries with diverse scientific and research cultures and agendas in collaborative research explain the EU-wide endeavor for some standardization and alignment of research efforts and methods. Overall, a large majority of Europeans believe national research activities in the EU Member States should be more coherent (TNS Opinion and Social 2005). Eighty three percent of surveyed Europeans believe there should be more coordination of these research activities across the national EU borders (TNS Opinion and Social 2005). The European Commission as a result proposed to stimulate the sharing of this knowledge across Europe's borders so that these research efforts can be jointly managed and integrated at the European level.

While overall the EU has a strong record of research, this record is a result of fragments of work across many institutions and universities. Many of these research efforts are not synchronized on the EU level, in fact, of all public sector research in the EU only about $20 \%$ of it takes place at the EU level, the rest takes place at the national or regional levels. Creating a single ERA is thought to contribute to a greater defragmentation of European scientific and technological activities.

Currently, the main development mechanism in the ERA is the 7th EU Framework Programme for Research and Technological Development (FP7) which bundles all research-related EU initiatives together under a common roof playing a critical role in achieving the goals of growth, competitiveness and employment. From the start of its first Framework Programme, the EU has been putting a lot of effort in increasing its market standing against its main competitors (primarily Japan and the USA). The EU Framework Programmes promote exchange and diffusion of scientific and technological knowledge through the development of collaborative practices across Europe. With S\&T research becoming increasingly more high-level, costly and complex, society resorts in many of these cases to collaboration and cooperation (including the research networking or increased researcher mobility) seen as an essential element in ensuring overall progress and development in the scientific field (Defazio et al. 2009). Some of the practical initiatives under this innovation policy determined at the Lisbon Summit integrate research capacities already existing in individual states through pan-European participation in collaborative projects in science and technology. Scientific cooperation in its different forms is coming to a new level. Since the European institutions have been given competence in the S\&T area, they have developed several initiatives in order to promote and coordinate European research and development (R\&D) efforts, create pan-European networks and stimulate mobility of researchers in Europe. The EU government strongly promotes the use of research groups and networks involving universities, research institutes, public organizations and private businesses. Most funding instruments introduced under the Framework Programmes (FPs) consider only proposals submitted by collaborative networks of researchers. While the FP instruments require researchers to apply for funding and to conduct research in networks, these instruments do not define any particular structures or forms for such collaboration or networking. This dedicated public funding has resulted in more than 17,000 multinational research projects with over 85,000 collaborations by laboratories across Member States (European Commission 1992).

The EU funding of different forms of research networking has an objective of tackling fragmentation of the national research activities across the EU Member States through 
promotion of cross-border collaboration between individual scientists and research organizations. A number of initiatives have been launched to facilitate the all-European coordination of fragmented research activities and programs across the EU States (for example, the European Technology Platforms and the ERA-NETs). One of the objectives for most of these funding schemes is to bring under one framework the fragmented national research programs in the EU States.

\section{COST: EU-funded research networking programs}

The biggest component of the FP7 is the Cooperation Programme which received 64\% of the overall FP7 budget (51 billion Euros). Under the FP7, the EU is financing a number of formal pre-competitive networking programs aiming at a better deployment of existing national research capacities via their inclusion in joint research initiatives. One such instrument focused on science and research networking and included in the FP7 Cooperation Programme budget is known as COST.

While COST currently supports about 200 research network projects at any one time, overall, through its projects, COST reaches out to over 30,000 researchers across Europe. Research collaboration in COST is based on Actions, which are formal research networks coordinating nationally funded research projects. COST networks in many cases are built around highly innovative and interdisciplinary research projects generally running for 4 years. Many EU funding programs generally support both the research itself and the coordination and networking activities. In contrast, COST supports financially only the actual network coordination related work and activities (such as travel costs, expenses related to organization of meetings, workshops, conferences, researcher exchanges or training schools). It explicitly does not support the research as such but focuses on the tasks facilitating greater results from the research supported by the individual European states. A standard COST Action is based on an official Memorandum of Understanding and it frequently consists of a standard range of collaborative activities such as meetings, conferences, short-term research exchanges (missions) and some outreach activities.

\section{EU investment in formal networking research programs}

Under the FP7, COST is set to receive a significantly increased budget of 250 million Euros to support its activities (up from 80 million Euros under the EU Framework Programme 6). Such a significant increase in the EU funding can be seen as a strong vote of confidence towards the COST programs as well as a recognition by the European Government of the importance of scientific networking to the academic community. When justifying the EU investment in the COST framework, the European Commission officials as well as the COST Action researchers involved mention a number of points: results generated by the scientists involved in COST Actions which are frequently presented at high-level international conferences, journal publications and books. There is also a long list of success stories (of how some COST Actions generate significant research results leading to new knowledge, patents, industrial applications, etc.) that is used to support the arguments why the COST framework is important to the ERA.

On the other hand, the recent COST Open Calls repeatedly confirmed a strong interest on the part of the European scientific community in COST activities. The almost 500 
preliminary proposals submitted for the third COST Open Call in 2007, from which only 25 new COST Actions were selected, represent a new overwhelming response on the part of the European scientific community. Such a strong response to the Open Calls indicates a need for an effective but light tool to network and coordinate research activities at the project level, bringing researchers together and letting them work out their ideas, thus contributing to reducing fragmentation in research investments in Europe.

The governments (and the general public) are generally willing to take S\&T research projects' value as a matter of faith and surprisingly only in the last decade has evaluation of publicly funded science outcomes started becoming a routine reality (Corley 2007). However, with research budgets reaching new unprecedented levels it is imperative to be able to provide evidence to justify the distribution of the funds and the choice of the programs that receive funding. As the formal scientific networking is both touted and perceived as an added value activity, this research will attempt to search for evidence that will either support or reject this perception. The existing literature does not yet provide a straightforward answer to the question as to whether or not such formal networking research projects actually lead to research outputs. Only a limited number of studies have attempted to test empirically these assumptions. It is suggested that research networking can be tricky and that it is not always well positioned to achieve its objectives (Godin and Gingras 2000).

The consistently strong interest from the European research community, high levels of satisfaction of researchers involved in COST Actions (see COST Customer Satisfaction Studies 2005 and 2007), and support of the EU government do not answer one question: Why should governments (and other funding sponsors) support scientific networking? Does it contribute to research and innovation? This research attempts to provide some insights into the applied S\&T outputs associated with the formal research networking projects such as COST Actions. There is a consensus that increasing levels of collaboration amongst academics produce 'better' results, and this generally means higher quality (Rigby and Edler 2005). However, the issue of collaboration (and especially networking) in research and its impact on research outcomes remain a contentious area with a wide variety of views of what roles such collaboration plays and its general implications for scientific performance (Rigby and Edler 2005). This research paper seeks to address this gap in existing literature by answering the following research question: Do researchers involved in research network teamwork actually achieve research outcomes which can be attributed to their participation in formal networking research projects, or is it just a bureaucratic novelty?

To address this question, this research paper will investigate research outputs attainable through participation in FNR projects by positioning it within the settings of the COST framework. The choice of the COST Actions for this study is justified by a number of reasons, one of which is the fact that these Actions are characterized by an intensive and structured approach to networking; COST Actions generally cover a range of all disciplines and scientific domains. Another reason is the significantly increased financial support by the European Commission (the greater demands for accountability) to the COST activities under the FP7.

\section{Research networking for results}

Collaborative research processes are generally expected to improve the process of knowledge production; however, the actual relationship between research networking 
and productivity is not evident. In fact, some even argue that some forms of research collaboration can sometimes have a negative impact on the level of research outputs (Landry et al. 1996). One of the reasons behind it is that research collaborations unavoidably take additional time and resources of participating collaborators (Landry and Nabil 1998). This additional burden does not necessarily (or automatically) ensure success of the collaborative project. Also, not all collaborative arrangements are necessarily able to meet original expectations and objectives.

Only a few studies focus on the productivity of research collaboration at the level of an individual researcher. Some studies focus on the impact of collaboration (Durden and Perri 1995; Gonzalez-Brambila and Veloso 2007; Godin 2003; Lee and Bozeman 2005; Rigby and Edler 2005; Shelton 2008) with most research considering the impact of research collaboration in general rather than in the specific context of formal research networking. Many studies focus on the importance of industrial funding to researchers in terms of their research performance (Gulbrandsen and Smeby 2005; Feller et al. 2002; Bozeman and Gaughan 2007). An examination of the impact of the research environment on research productivity of academic faculty is provided by Conn et al. (2005). Their findings suggest that certain research environments and infrastructures can significantly improve one's research standing.

A recent study viewed the impacts of collaborative research on the productivity of participants in research collaborations funded by the National Science Foundation (Cummings and Kiesler 2007). The authors analyzed the coordination activities and project outcomes of such research collaborations in terms of division of responsibilities, knowledge transfer and predicted project outcomes. Their research findings suggest that larger numbers of participants in collaborative projects result in fewer coordination activities, which in turn results in fewer research outcomes. The study only considered outputs directly related to participation in collaborative projects. It specifically focused on inter-university collaboration and therefore only analyzed the outcomes at the institutional level. A different view on researcher productivity within collaborative research was taken by Landry, Traore \& Godin in their 1996 research paper. Some of their results indicate that research collaboration can indeed improve or facilitate researcher productivity. The authors further suggest that the biggest impact on researcher performance is in the case of collaborations with industry (rather than with other peers or other academic institutions). Interestingly, the productivity also varied according to the collaborators' geographical closeness as well as their research discipline (Landry et al. 1996).

A number of studies have attempted to determine the relationship between the levels of funding and researcher productivity (Godin 2003; Gulbrandsen and Smeby 2005). One such study considers whether there are relationships between the levels of funding and researcher productivity (Godin 2003). The author argues that the research productivity grows with the level of funding, at least in case of those researchers who are in receipt of higher levels of funding. Another interesting observation is that the junior researchers' productivity increases steadily as soon as they obtain research funding and over time tends to compare favorably with that of established researchers. At the same time, the productivity of researchers whose research grant applications have been rejected tends to stagnate subsequently. There is also evidence in the literature of a relationship between researchers' performance and the availability and size of research 
funding (Lee and Bozeman 2005). It has been suggested that this relationship can be affected by both the stage of the career as well as the amounts of funding (Godin 2003). The results relate researcher productivity to the researchers' status or academic field. Bonzi (1992) further notes that full professors increase their productivity greater than do assistant and associate professors. Among other findings, the study mentions that an increase in the productivity for males is lower than that for females (Bonzi 1992). Different research fields also displayed differences in improvements in research productivity over time. Some research fields (like science and mathematics) tend to display a greater improvement of research productivity than others (social sciences) do.

Defazio et al. (2009) examined the relationships between the collaborative incentives and researcher productivity in the context of EU-funded research networks. The authors found that in spite of the generally observed positive relationship between the impact of funding and researcher productivity, the overall impact of collaborative activities within the funded networks is less significant (2009). However, when Defazio et al. (2009) distinguished between the pre-, during- and post-funding periods, they identified some important differences. Collaboration during the funding period did not result in an increase of research productivity; however, in the post-funding stage, the impact of collaboration on the productivity was both positive and significant. An important conclusion from the study is that while collaborations (formed specifically for exploiting funding opportunities) were not effective at improving researcher productivity in the short term, they still contributed to promoting effective collaborations in the longer term. Their findings are limited because of the difference between the type of research collaborations reviewed by Defazio et al. (2009) and formal networking research projects such as COST Actions. In the research projects reviewed by Defazio et al. (2009), funding support covers the costs of the project (the cost of managing the project, the cost of equipment and all project-related personnel costs, including their travel and subsistence. Other research networks were in receipt of a grant up to $100 \%$ of the cost for hiring early-stage researchers, for organizing conferences and meetings that involve the other partners of the network (Defazio et al. 2009). The researchers within the research networks reviewed by the authors were availing of general research funding, while researchers participating in collaborative Actions funded by COST do not receive any actual funding for conducting research; they only receive funds for facilitating research networking (meetings, exchanges, training schools, etc.).

\section{Measuring S\&T performance}

Both organizations and individual researchers have some flexibility in deciding which forms and models of collaboration to choose based on the possibilities that they offer. This flexibility allows them to choose models ranging from alliances to joint projects and ventures, as well as allowing them to respond quickly to changes in their research field, market or industry conditions. However, the actual outcomes, impact and effectiveness of such knowledge exchange are difficult to evaluate and measure (Polt et al. 2001). Assessing a project based on its outcomes is a possibility and has been explored at least to some extent, yet it is still unclear what impact it has on individual researchers involved in the project. Recent studies on collaboration (especially collaborative arrangements involving interaction with industrial science) confirm the importance of collaboration in generating scientific and technological outputs, and suggest that 
such collaboration is capable of providing both individuals and organizations with benefits outweighing its costs (Rigby and Edler 2005). The analysis therefore starts with an assumption that most research collaborations facilitate creativity through the exchange of opinions and constructive dialogue (e.g., different forms of peer reviewing) and that is often one of the reasons why researchers collaborate (van Zee and Engel 2004).

Based on this understanding, many of the assessment studies generally build performance assessments of collaborative projects around a number of tangible outputs such as publications and, less frequently, patents. Many of these studies on collaborative practices carried out by scholars in the field of research policy still maintain a strong assumption that joint publications are the best indicator of research collaboration. However, there is now a growing realization that the phenomenon of research collaboration has only been studied on the macro level, and rarely on the micro level (Rigby and Edler 2005). Some studies on performance measurement of collaborative activities focus in general on aspects related to information generation and dissemination. While research collaborations are based on information flows between collaborating partners, in the specific case of the field of technology transfer, it also refers to either patents, industrial applications, technology licensing or even formation of academic start-ups (Philbin 2008). Other commonly observed benefits derivable from collaboration are joint learning, consensus and accommodation of mutual requirements, field orientation and, importantly, improvements in networking skills together with improvements in scientific and technological skills. The different types of research collaborations can result not only in joint publications but also in a large variety of other research outputs from proprietary benefits, new instrumentation, methodologies to prototypes, patents, intellectual property rights (IPRs) and start-ups, as well as technological innovation, continued support of research programs, student exchanges and projects, and graduate student recruitment (Barnes et al. 2002).

Improved performance measures are becoming especially important due to the everincreasing accountability of research organizations to the funding providing sources as well as to their stakeholders. It has been argued that the use of balanced scorecards can potentially address this need for metrics when assessing the performance of a research collaboration (Philbin 2008). Research also stresses the need for tangible and intangible measures in performance management as this can help identify enhancements in knowledge and social development (2006). According to Koontz and Thomas (2006), many respondents (both academics and managers) expressed a strong interest in measures and indicators including quantifiable parameters, which could assist in improving existing collaborations. A large percentage of project organizers implement a system that tracks the outputs of the project as a reporting requirement set by their funding organization. Most of government-sponsored research projects are required to implement monitoring programs, the results of which are later used in decisions related to future funding approvals by public officials. Many of the EU Framework research projects, for example, tend to require a regular progress report to the European Commission. In some cases, it is the public officials, who decide on the standards for these measures or actively collaborate with researchers in the setup of such measures. A clear monitoring system helps to prevent confusion at a later stage of the project. In many cases, these outputs are discussed at the implementation stage of the project. This allows organizations to monitor and record the immediate results or outputs of their activities. Such a formal 
system for tracking outputs keeps track and control of project activities and changes, allows project managers to be accountable to the funding organizations and other stakeholders, helps in the understanding lessons learnt, as well as providing tools for assessing project outcomes at a later (or final) stage.

Through such collaborative participation, organizations gain opportunities to access complementary external knowledge and other resources as collaboration with external players provides the firm with access to knowledge which it could not produce internally (Lundvall 1992). This is often the case in knowledge-intensive industries or where knowledge of several research fields is required and therefore a single firm would find it challenging or even impossible to keep up with the latest developments in all related fields.

\section{Applied research outputs}

Scientific and technological collaborative arrangements and agreements turn into a crucial channel for transferring knowledge internationally. However, some researchers believe these knowledge flows are mostly invisible and leave no traces by which they can be measured (Krugman 1991), while other researchers respond that some knowledge flows can be measured with tracking of patents (Jaffe et al. 1993). The number of patents and the number of publications among some of the most often indicators used in official evaluation reports for composite indicators of performance present important key information which should not be taken lightly (European Commission 2005).

Patents represent a system of social institutions protecting intellectual property over technology. The very existence of such institutions became a reason for publicizing research knowledge (Forero 1999). While the owner of the patent can collect the business-related rents from these patents, everyone else also can build on this knowledge. Patents and IPRs can be used in a number of different ways: one way is to prevent everyone else from accessing this knowledge and another way is to prevent potential competitors from directly obtaining rents from it, while having to disclose (Forero 1999). In recent years, patents owners use the patent to prevent full disclosure. The downside of this is that this prevents researchers from using large portions of the already existing scientific and technological knowledge as input for the research work (Forero 1999).

As research collaborations often include a range of non-academic participants, it should be noted that for all participants to achieve mutual benefit they would have to ensure an appropriate balance between academic objectives and non-academic (industrial or business) priorities (Barnes et al. 2002). Researchers highlight the importance of considering proprietary benefits and that is at least ensuring benefits proportionate to investment, as well as planning for achievement of tangible outputs during the early stages of the projects (Barnes et al. 2002). Effective management of research collaborations includes work on maintaining the interests and commitments of different categories of participants including those from the academy, industry and government.

Across all economic sectors, many of the industry-academy collaborations are of a research nature and mainly involve applied research with industry providing funding in exchange for intellectual contribution from the academic counterparts to the project (Butcher and Jeffrey 2005). In some instances, research reports examples of frustration expressed by the industrial participants who perceive progress as slow within the 
project (Barnes et al. 2002); often these participants perceived their academic counterparts as not concentrating enough on tangible outputs. According to Dawson (1997), industrial participants often equate tangible outputs with actual progress, where tangible outputs are seen as a means of increasing motivation. Much of the disappointment expressed by the industrial participants was mostly around the difficulty justifying their and partners' investment of resources and time in the project through early confirmation of project value. This dissatisfaction also suggests the importance of planning for tangible outputs at an early stage of the collaborative project as a possible measure of maintaining the interest of non-academic partners (Barnes et al. 2002).

The business and industrial partners are generally interested in opportunities to commercialize newly created knowledge. However, the important question is how to commercialize the science. Scientists often establish new spin-offs to take their patented ideas to the next step - commercialization (2002). This is a universal phenomenon although there is a relationship between the likeliness of inventions being patented based on the geographical location. Related statistical data suggests that up to $94 \%$ of all patents in 2000 were registered in advanced western countries (Archibugi and Pietrobelli 2003). However, with the increased popularity of collaborative arrangements, there is growth in the number of patents registered elsewhere, too.

A patent study carried out by Breschi (2000) showed that the geographical concentration of innovative activities across the European Union is highly dependent on the sector. Recent data on science and technology in the EU confirmed that the S\&T knowledge bases are highly diversified in the EU (European Commission 2005). It also showed that the S\&T outputs when measured by scientific publications and patents are significantly more diversified in the EU than in the US or Japan both in terms of scientific disciplines and industrial fields. One should bear in mind that as such, scientific research does not produce applied outcomes to the same extent as solely industrial $R \& D$ does, as well as it varies across scientific disciplines (Frenken 2002). But while the majority of patent applications are still submitted by businesses, there is also a new trend involving academic institutions. A recent study suggests that after universities in the US were given the right in 1980 (the Bayh-Dole Act) to patent inventions (funded by the government), this resulted in a significant increase in patents and in particular in licensing of university patents (Adams et al. 2001). Another study measures the intrinsic relational structure of knowledge flows through variables which among others included co-patent applications as an indicator of marketable innovations (Maggioni and Uberti 2007). Adams et al. (2001), by looking at R\&D in biotechnology, concluded that research collaborations which involve both industry and universities tend to yield a higher ratio of patents to $R \& D$ than internal $R \& D$ efforts.

Existing literature provides many examples of the use of patents in the evaluation and assessment field (Jaffe et al. 1993; Arvanitis et al. 2008). Patent statistics are now generally accepted and often used as an indicator of technological capability. However, a recent study by Coombs and Bierly (2006) looked at the effectiveness of some technological measures using patent citations and came to a conclusion that the total number of patents is not usually a valid measure of technological capability. Previous research based on patent analysis suggests that in the case of firms, the usefulness of research and development collaborations tends to increase when firms differ significantly in their knowledge bases (Frenken et al. 2005). While patents can be considered to be a 
valid measure of codified knowledge, at the same time patents do not necessarily capture all the dimension of internal knowledge mainly because of the elements of noncodified knowledge (Arora and Gambardella 1990). This was addressed by Murray (2002) who proposed a new methodological approach which uses a patent-paper pair rather than using patents and publication as separate indicators. Patents only reflect the formalized component of scientific and technological knowledge and formalized knowledge-generating institutions do not necessarily represent the only existing component of technological change. Archibugi and Pietrobelli (2003) suggest that the making of national S\&T capabilities needs the ability to learn or maybe even imitate the knowledge created in other countries. Recent applications for international patents show a significant increase in international exploitation of nationally created knowledge (Edler and Boekholt 2001).

Some believe that the best output measure of scientific and technological capability would be the number of new products and improved processes (Coombs and Bierly 2006). The same researchers warn that this measure is somewhat difficult to implement as it is not always easy to differentiate truly new products from other changed products and the information about the new products may not be openly available because of the certain degree of secrecy surrounding many production processes. In other cases, research results can be utilized to some extent, yet they never become full patents or industrial applications. However, some forms of utilization of research results, industrial applications and patents often occur at different research stages of a project. Similarly, not all S\&T research activities lead to patents as some result in forms such as industrial applications. Therefore, instances of utilization of R\&D results as well as different forms of industrial application of research results can serve as a measure of basic forms of research as they measure outputs at the earlier stages of S\&T collaboration. As a result, these outputs (different forms of utilization of results at some level and industrial applications) can complement the use of patents as indicators for evaluating $R \& D$ processes resulting in the development of new products or even improved processes.

Even though the use of patents for evaluating collaboration is somewhat widely accepted, there are certainly some disadvantages in using solely this approach. Generally, using patent indicators can never be more than a partial indicator of S\&T collaboration performance. With a large number of researchers accepting patents as a strong indicator of R\&D performance, it is important to bear in mind that when looking closer at different forms of collaborations (such as formal networking research projects) one has to consider forms of applied collaborative outputs other than patents. Some of the numerous collaborations even in scientific fields such as material science do not always result in patents and so these collaborations would therefore not be detected through the count of registered patents. In other cases, these collaborations result in other types of applied outputs such as industrial application of research results or their utilization at different levels (national/international).

\section{Conclusions}

COST is the oldest running pan-European intergovernmental framework facilitating research and scientific networking of nationally financed research projects at the European level. It was established at the Conference of European Research Ministers in 
1971. COST is seen by many as an important and complementary instrument within the European research funding system which plays an ever-increasing role as a facilitator for participation in larger research activities (Technopolis 2004). COST was also recently recognized by the EU Council as essential to the creation of the true spirit of cooperation across Europe (EU Council 2009). Yet, despite the EU has further committed to invest further 250 million Euros into the COST framework over the course of the FP7 only a very few studies examined the impact of participation in formal research networking projects on research productivity in terms of applied S\&T outputs (e.g., patents or industrial applications).

This paper has examined whether formal networking programs contribute to facilitating innovation in the European Research Area (ERA) by enabling Science \& Technology (S\&T) participants to achieve anticipated research outcomes from their involvement in such programs. The results suggest that patents are achieved to some extent by at least one in every ten FNR participants, while some forms of industrial application are achieved by at least four out every ten FNR participants. These results are in line with the conclusions drawn by Nelson (2001) who argues that patenting in academic setting can result in higher costs of research. According to Gulbrandsen and Smeby (2005), in some scientific fields, researchers are somewhat skeptical towards any further increase in patenting since it can create new barriers to further research and to innovation. At the same time, industrial applications and patents are perceived as 'inapplicable' by a significant share of survey participants. So not all FNR projects can lead to some form of patents or industrial applications. This is in agreement with Bozeman and Melkers (1993) who found that commercial outputs (such as patents) can be of varying utility to different groups of researchers.

Research generally supports the view that participation in scientific networks can lead to effective innovations and this interaction with the scientific community can be crucial for a company's ability to incubate and commercialize new ideas (MIT 2002). It is well accepted that collaborative research efforts including those in a form of formal networking research projects can result in a wide range of research outputs many of which can be perceived to surface years after the actual collaboration takes place. However, approximately nine out of ten FNR participants reported utilizing FNR project results at the national level. These results suggest that the COST funding concept can be a flexible yet efficient tool for networking and coordination of the fragmented nationally funded research projects and in many cases leads to at least some applied S\&T outputs.

This paper has examined the patterns of applied S\&T outputs achievable as a result of participation in formal networking research projects funded by the research schemes which explicitly do not support any direct research expenses other than those immediately associated with research networking (such as COST). The identified patterns indicate that a light funding framework such as COST, which is built primarily on the proposals coming from the European researchers themselves, could ensure a needed support for the networking and the coordination of research activities, which lead to a wide range of applied S\&T outputs. The main objective of the COST funding is only to establish the actual network and to establish the organizational and operational foundation for the research. The overall COST funding per each COST Action on average accounts for only $1 \%$ of the national funding in each Action. Yet, despite the small scale of the COST funding, researchers tend to attribute some of the three research outputs 
(patents, industrial applications and utilization of research results at the national level) to their participation in FNR projects.

This paper is one of first attempts to examine empirically the extent to which some of the S\&T outputs are achieved through (or are attributed to) participation in FNR projects. However, the results raised additional questions that will have to be addressed in future research papers. As academic participants generally achieve fewer industrial applications and patents, future research should control for FNR project participants' professional background (i.e., academic, industry, business, government) to determine to what extent the cases are in FNR projects. In addition, some S\&T outputs may be only applicable to specific research fields. For example, in humanities, one would rarely expect to develop an industrial application. Therefore, future research should consider to what extent FNR project participants from different scientific domains vary in their achievement of certain S\&T outputs. Similarly, future research can focus on the differences in achieving S\&T outputs by participants with different educational backgrounds, research experience or even from different geographical regions.

\section{Methods}

\section{Data and sample}

An analysis is conducted on patterns of applied S\&T outputs achievable in FNR projects. Many researchers are involved in multiple research activities. Attributing some research outputs can be easier and more verifiable than others. One of the assumptions here is that individual FNR participants (researchers with current and previous experience of formal networking research projects) in many cases are best informed in terms of applied S\&T outputs which they achieve and whether these outputs can be attributed to a specific research project. This study intends to explore and evaluate particular $R \& D$ outputs associated with formal networking research programs such as COST Actions (at the level of an individual researcher). This evaluation research employs a survey methodology. A large-scale survey addressed actual participants of the formal research networking projects (COST Actions). The survey employed mainly Internet-based questionnaires of close-ended questions, which primarily used quantitative ordinal scales.

The study was conducted in 2006 using a database of research project participants (previous and current) associated with the EU-funded formal networking research projects. Emails with links to a web-based questionnaire were sent out to 7,001 project participants from the database (participants with correctly registered email addresses). A total of 2,173 completed questionnaires have been returned giving a $31 \%$ response rate. One of the two parts of the questionnaire sought socio-demographic information, including respondent's level of education, research experience, professional background/affiliation, etc. The second part of the survey asked to what extent the respondents have achieved each of three research outputs (patents, industrial applications and utilization of research results at the national level) as a result of their involvement in FNR projects. The respondents were based in academia (63.7\%), laboratories and research institutes (25.4\%), business/industry (4.0\%), government (5.7\%) and elsewhere (1.2\%).

Among the survey participants, $76 \%$ are male and $24 \%$ are female; $87.2 \%$ hold a doctoral degree or equivalent, while $12.8 \%$ do not. Nearly a quarter of all respondents were involved in more than one FNR project at the same time $(22.8 \%)$, while $77.2 \%$ of 
researchers were only involved in one FNR project. This research adopted a composition of macro geographical (continental) regions, geographical sub-regions, and selected economic and other groupings as suggested by the UN Statistics Division ${ }^{\mathrm{a}}$. In terms of this geographical distribution, the largest groups of respondents are from Western Europe (28\%), Southern Europe (27.1\%), Northern Europe (25.6\%), as well as Eastern Europe (16\%), and smaller groups of respondents are from Turkey/Israel and elsewhere (3.3\%). Also, 18.3\% of respondents work in Chemistry and Molecular Sciences and Technologies (18.5\%), 16.6\% work in Food and Agriculture, 13.8\% of respondents work in the area of Materials, Physical and Nanosciences, $11 \%$ work in the field of Forests, their products and services, $10.2 \%$ work in Transport and Urban Development, 9.9\% work in Earth System Science and Environmental Management, 7.1\% work in the field of Biomedicine and Molecular Biosciences, $6.5 \%$ work in the field of Individuals, Societies, Culture and Health, while 5.6\% of respondents work in the field of Information and Communication Technologies, and only less than $1 \%$ of all respondents work in the interdisciplinary field $(0.8 \%)$.

\section{Measuring S\&T output productivity}

This survey of FNR project participants was formed to detect which research networking S\&T outcomes/outputs are attributed by actual participants to their involvement in these projects. A number of recent management studies examined the use of quasi-perceptual measures - hybrids between the operational definition measures and perceptual measures (Ketokivi and Schroeder 2004). In such quasi-perceptual measures, the content of the measure is defined according to an operational definition, but the measurement units are defined as perceptual (Ketokivi and Schroeder 2004). Some argue that asking respondents directly to provide exact figures (exact number of patents, etc.) often results in high non-response rates (1997). As a result, quasi-perceptual measures allow the same questions in a less direct manner, for instance, using scaled measures (Ketokivi and Schroeder 2004). To operationalize the S\&T productivity in the context of FNR projects, a list of applicable S\&T outputs (patents (ST1), industrial applications (ST2) and utilization of project results on the national level (ST3)) was created based on the reviewed literature, and was later confirmed by the field experts and participants with experience of formal networking programs. The questionnaire asked respondents to indicate to what extent they have achieved each of the listed research outputs as a result of their involvement in FNR research projects. The categories of outputs included patents, industrial applications and utilization of research results at the national level. The answers ranged from 1 ('not at all') to 5 ('fully').

\section{Patents (ST1)}

Respondents were asked to indicate to what extent they had achieved patents as a result of their participation in formal networking research projects (see Figure 1). The patent data are characterized by the following measures of central tendency: mean (1.67), median (1.0) and a positive skewness value (1.324). Further, the data indicate that $44.3 \%$ of 2,173 participants reported that patents do not apply ('not applicable') to them as a FNR output. Only $0.6 \%$ of respondents reported achieving patents 'fully', while further $2.8 \%$ of respondents achieved patents 'to a great extent'. Further, $8.2 \%$ of respondents reported achieving patents at least 'in part', and another group of $9.7 \%$ reported achieving patent only 'to a small extent'. Over a third of all respondents (34.3\%) reported that they did 'not at all' achieve patents as a result of their FNR project activities. 


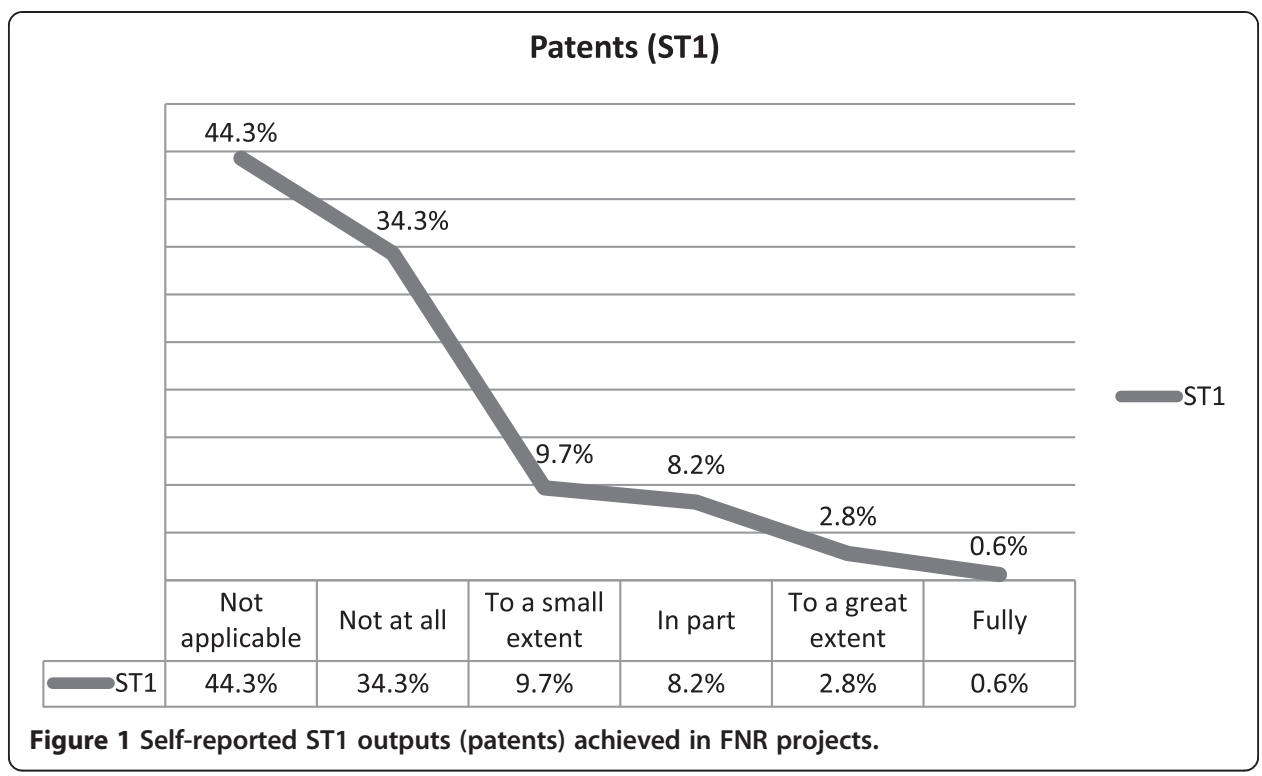

When the respondents who reported patents as inapplicable research outputs were excluded from the analysis (44.3\%), the remaining respondents (55.7\%) were distributed as follows: those who did 'not at all' achieve any patents (34.3\%), those who achieved but only 'to a small extent' (9.7\%), those who achieved patents 'in part' (8.2\%), those who achieved 'to a great extent' (2.8\%) and finally, those respondents who achieved this output 'fully' (0.6\%).

\section{Industrial applications (ST2)}

Respondents were asked to indicate to what extent they had achieved industrial applications (ST2) as a result of their participation in formal networking research projects on the scale from 1 ('not at all') to 5 ('fully') or if the output is not applicable to their participation in FNR project (see Figure 2). This dataset on industrial applications is characterized by the following measures of central tendency: mean (2.24), median

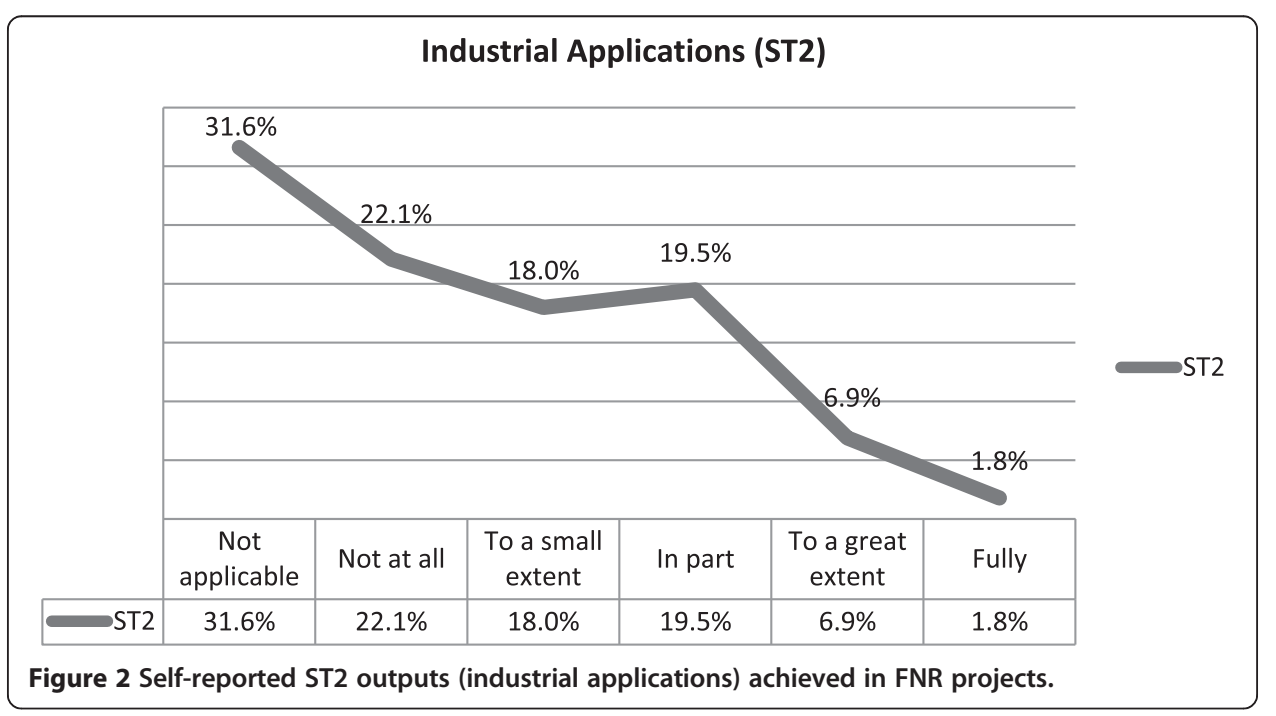


(2.0), and a positive skewness value (0.459). Out of 2,173 respondents, $31.6 \%$ reported that industrial applications do not apply ('not applicable') to their FNR participation.

A small group of $1.8 \%$ out of all respondents reported achieving industrial applications 'fully' as a result of their FNR projects. Another group (6.9\%) of subjects has achieved industrial applications 'to a great extent', while another group (19.5\%) has achieved industrial applications at least 'in part'. A group (18.0\%) of respondents have achieved industrial applications only 'to a small extent'. About one fifth of all respondents (22.1\%) reported 'not at all' achieving industrial applications as a result of their involvement in the formal networking program.

When the respondents who reported 'ST2' (industrial applications) as inapplicable research outputs were excluded from the analysis, the remaining respondents were distributed as follows: those who did 'not at all' achieve any industrial applications (32.3\%), those who achieved but only 'to a small extent' (26.4\%), those who achieved industrial applications 'in part' (28.5\%), those who achieved output 'to a great extent' (10.2\%), and finally, those respondents who achieved this output 'fully' (2.6\%).

\section{Utilization of research project results at national level (ST3)}

Finally, respondents were asked to indicate to what extent they had achieved the 'utilization of networking research project results at national level (ST3)' as a result of their participation in formal networking research projects (see Figure 3). When the respondents who reported 'ST3' outputs (utilization of project results at the national level) as inapplicable research outputs were excluded from the analysis, the rest of the respondents were distributed as follows: those who did 'not at all' achieve ST3 (6.8\%), those who achieved but only 'to a small extent' (15.6\%), those who achieved ST3 outputs 'in part' (35.1\%), those who achieved 'to a great extent' (29.9\%), and finally, those respondents who achieved this output 'fully' (10.8\%).

The mean of the sample is 3.22 , its median is 3.0 , and a negative skewness value $(-0.249)$. The negative skewness value indicates a negative skewed distribution in the responses to the question. Less than 5\% (4.9\%) of the respondents reported that this

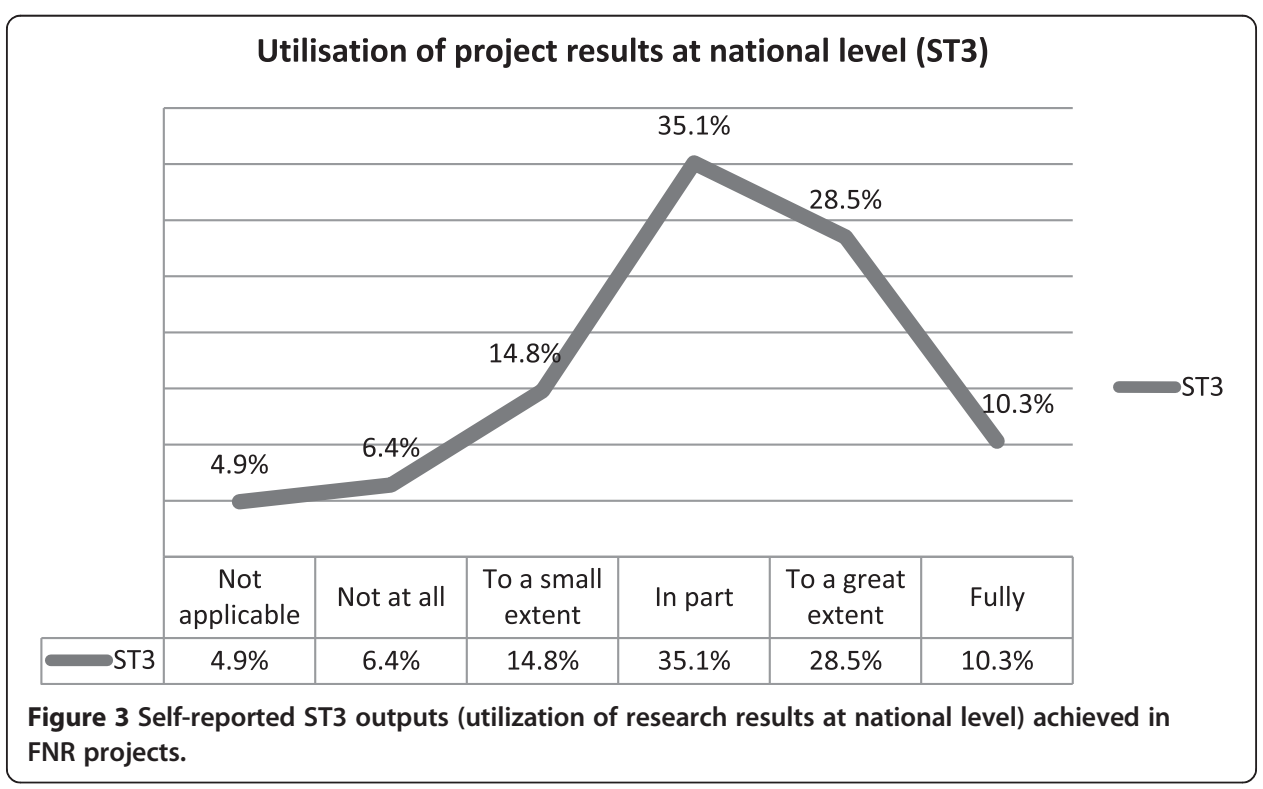


output does not apply to them. Further, $10.3 \%$ of the current participants have 'fully' achieved utilization of networking research project results at national level as the result of their involvement in formal networking research project. Less than a third (28.5\%) of subjects have achieved utilization of networking research project results at national level to a 'great extent', while nearly a third of all respondents (35.1\%) have achieved utilization of networking research project results at the national level at least 'in part'. A group (14.8\%) of respondents have achieved utilization of networking research project results at national level only 'to a small extent'. A relatively small part of all respondents (6.4\%) report not achieving this output at all (utilization of research results) as a result of their involvement in the formal networking program.

\section{Research outputs attributable to formal networking programmes}

This paper presents data collected from a survey of participants involved in formal networking projects. The survey was designed to assess whether project participants attribute certain applied S\&T outputs to their participation in formal networking research projects. For each of the listed outcomes, the respondents were asked to indicate whether they have reached it fully, to a great extent, in part, to a small extent, have not reached it at all or if any of the outcomes is not applicable to them (Likert items). The respondents were offered a list of three items (research outputs) and their responses to a single fivelevel Likert item in this research paper are treated as ordinal data: patents (ST1), industrial applications (ST2) and utilization of project results at national level (ST3).

The responses have been further grouped into three categories: group 1 (listed S\&T outputs not achieved at all, or are not applicable), group 2 (the outputs are achieved by participants to a small extent or in part) and group 3 (the outputs are achieved to a great extent or fully). These grouped results are presented in Figure 4. In total, 3.4\% of participants have reported achieving patents fully or to a great extent as a result of their networking within the scope of the program. Only $17.9 \%$ of respondents managed to achieve patents in part or to a small extent. The large majority of respondents (78.7\%) did not achieve ('not at all' and 'not applicable') any patents as a result of their participation in networking projects. In terms of industrial applications, $8.7 \%$ of the participants have reported achieving these results 'fully' or 'to a great extent' as a result of

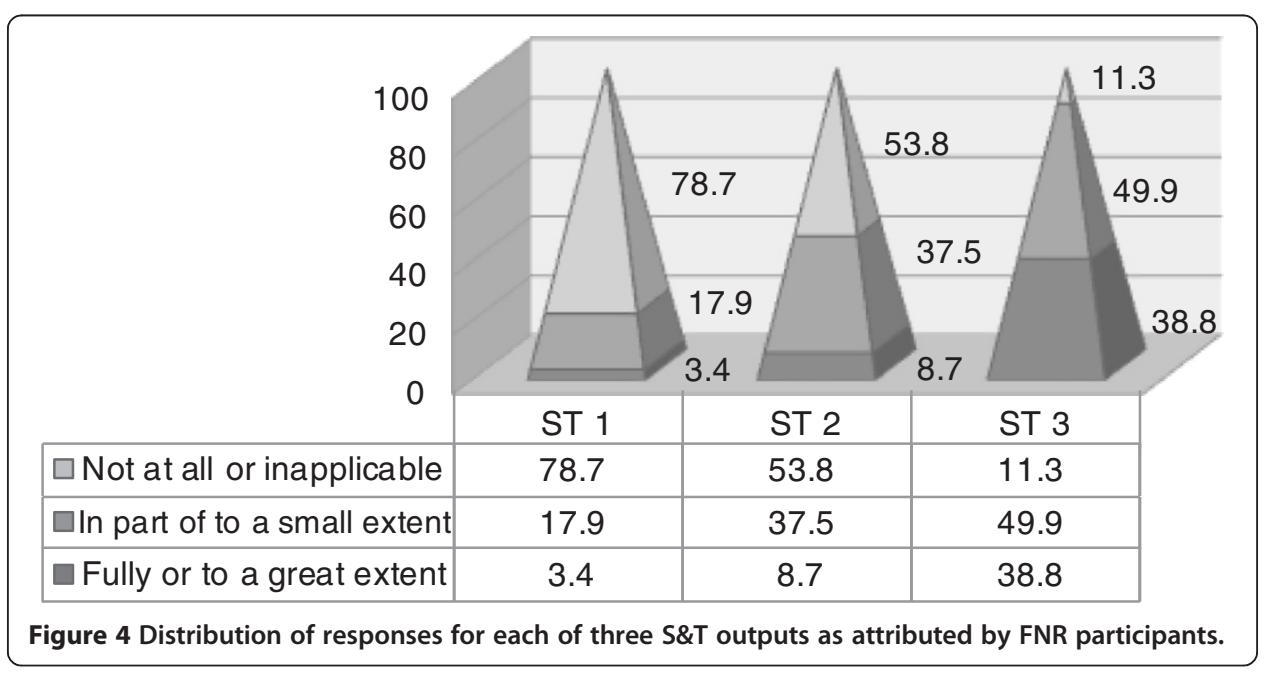


their networking within the scope of the program. At least, 'to some extent' (in part or to a small extent), industrial applications have been achieved by $37.5 \%$ of all respondents.

The remaining respondents (53.8\%) did not achieve ('not at all' and 'not applicable') any industrial applications because of their participation in networking projects. Over one third of all participants (38.8\%) have reported achieving utilization of networking research project results at national level 'fully' or 'to a great extent' as a result of their participation in FNR projects.

Nearly a half of all respondents (49.9\%) achieved utilization of project results at the national level ('in part' or 'to a small extent'); while the rest of the respondents (11.3\%) either did not achieve these research outputs at all or reported that utilization of research results at the national level were not applicable to their participation in FNR projects.

\section{Endnote}

${ }^{a}$ See http://unstats.un.org/unsd/methods/m49/m49regin.htm\#europe.

\section{Abbreviations}

COST: European Cooperation in Science and Technology; EC: European Commission; ERA: European Research Area; EU: European Union; FNR: Formal networking research; FP7: EU Framework Programme 7 for Research and Technological Development; IPR: Intellectual property rights; R\&D: Research and development; S\&T: Science and technology.

\section{Competing interests}

The authors declare that they have no competing interests.

\section{Authors' contributions}

RR conceived the study, gathered the data, drafted the manuscript and performed the statistical analysis. LB contributed to the research design, coordination, and final editing. Both authors read and approved the final manuscript.

\section{Acknowledgements}

The authors would like to thank Dr Martin Grabert (former COST Office Director) and Dr Wolfgang Obert (former COST Deputy Director) for allowing this study to be conducted, making results of COST surveys available, and facilitating this research.

\section{Disclaimer}

The opinions expressed are those of the author(s) only and should not be considered as representative of the European Commission's official position.

\section{Author details}

${ }^{1}$ European Commission, Joint Research Centre (JRC), Institute of Prospective Technological Studies (IPTS), Seville, Spain.

${ }^{2}$ School of Business, Trinity College, Dublin, Ireland.

Received: 23 July 2013 Accepted: 24 January 2014

Published: 20 Feb 2014

References

Adams, JD, Chiang, EP, \& Starkey, K. (2001). Industry-university cooperative research centers. The Journal of Technology Transfer, 26, 73-86.

Alders, C, Haverkort, B, \& Van Veldhuizen, L. (1993). Linking with farmers: networking for low - external - input and sustainable agriculture. London: Intermediate Technology Publications.

Archibugi, D, \& Pietrobelli, C. (2003). The globalisation of technology and its implications for developing countries: Windows of opportunity or further burden? Technological Forecasting and Social Change, 70(9), 861-883.

Arora, A, \& Gambardella, A. (1990). Complementarity and external linkages: the strategies of the large firms in biotechnology. The Journal of Industrial Economics, 38(4), 361-379.

Arvanitis, S, Kubli, U, \& Woerter, M. (2008). University-industry knowledge and technology transfer in Switzerland: what university scientists think about co-operation with private enterprises. Research Policy, 37(10), 1865-1883.

Barnes, T, Pashby, I, \& Gibbons, A. (2002). Effective university - industry interaction: a multi-case evaluation of collaborative R\&D projects. European Management Journal, 20(3), 272-285.

Bonzi, S. (1992). Trends in research productivity among senior faculty. Information Processing \& Management, 28(1), 111-120.

Bozeman, B, \& Gaughan, M. (2007). Impacts of grants and contracts on academic researchers' interactions with industry. Research Policy, 36(5), 694-707.

Bozeman, B, \& Melkers, J. (eds.) (1993). Evaluating R\&D impacts: methods and practice. Norwell, MA: Kluwer Publishing.

Breschi, S. (2000). The geography of innovation: a cross-sector analysis. Regional Studies, 34, $213-229$. 
Butcher, J, \& Jeffrey, P. (2005). The use of bibliometric indicators to explore industry-academia collaboration trends over time in the field of membrane use for water treatment. Technovation, 25(11), 1273-1280.

Conn, VS, Porter, RT, McDaniel, RW, Rantz, MJ, \& Maas, ML. (2005). Building research productivity in an academic setting. Nursing Outlook, 53(5), 224-231.

Coombs, JE, \& Bierly, PE. (2006). Measuring technological capability and performance. R\&D Management, 36(4), 421-438. $10.1111 / j .1467-9310.2006 .00444 . x$.

Corley, EA. (2007). A use-and-transformation model for evaluating public R\&D: Illustrations from polycystic ovarian syndrome (PCOS) research. Evaluation and Program Planning, 30(1), 21-35.

COST. (2007). COST contributes to the consultation on the EC green paper on "the Era: New Perspectives": the role of COST in the European Research Area. Brussels: COST.

Cummings, JN, \& Kiesler, S. (2007). Coordination costs and project outcomes in multi-university collaborations. Research Policy, 36(10), 1620-1634.

Dawson, P. (1997). From technology research to the practice of group-based manufacturing under multi-partner projects. Human Systems Management, 16, 35-42.

Defazio, D, Lockett, A, \& Wright, M. (2009). Funding incentives, collaborative dynamics and scientific productivity: evidence from the EU framework program. Research Policy, 38(2), 293-305.

Durden, G, \& Perri, T. (1995). Coauthorship and publication efficiency. Atlantic Economic Journal, 23(1), 69-76.

Edler, J, \& Boekholt, P. (2001). Benchmarking national public policies to exploit international science and industrial research: a synopsis of current developments. Science and Public Policy, 28(4), 313-321.

European Commission. (1992). La recherche aprés Maastricht: un bilan, une stratégie. Communication de la Commission au Conseil et au Parlement européen SEC(92) 682 final. Luxembourg: Office for Official Publications of the European Communities.

European Commission. (2005). Key Figures 2005. Towards a European Research Area: Science, Technology and Innovation (KI-NA-21264-EN-C). Luxembourg: Office for Official Publications of the European Communities.

European Commission. (2009). 2020 vision for the European Research Area. Research Policy (KI-78-09-595-EN-D). Brussels: European Commission.

EU Council. (2009). Official Journal of the European Union. Conclusions of the Council on the definition of a '2020 vision for the European research area' (2009/C 25/01). Luxembourg: Office for Official Publications of the European Communities.

Feller, I, Ailes, CP, \& Roessner, JD. (2002). Impacts of research universities on technological innovation in industry: evidence from engineering research centers. Research Policy, 31(3), 457-474.

Forero, CP. (1999). Knowledge access and collaboration in scientific research, In the ESF-IIASA-NSF workshop: building the virtual house of Salomon: digital collaboration technologies, the organization of scientific work and the economics of knowledge access. Laxenburg, Austria: IIASA.

Frenken, K. (2002). A new indicator of European integration and an application to collaboration in scientific research. Economic Systems Research, 14(4), 345-361.

Frenken, K, Hölzl, W, \& Vor, F. (2005). The citation impact of research collaborations: the case of European biotechnology and applied microbiology (1988-2002). Journal of Engineering and Technology Management, 22(1-2), 9-30.

Godin, B. (2003). The Impact of Research Grants on the Productivity and Quality of Scientific Research. INRS Working Paper No. 2003, Ottawa.

Godin, B, \& Gingras, Y. (2000). Impact of collaborative research on academic science. Science and Public Policy, 27, 65-73.

Gonzalez-Brambila, C, \& Veloso, FM. (2007). The determinants of research output and impact: a study of Mexican researchers. Research Policy, 36(7), 1035-1051.

Gulbrandsen, M, \& Smeby, JC. (2005). Industry funding and university professors' research performance. Research Policy, 34(6), 932-950

Jaffe, AB, Henderson, R, \& Trajtenberg, M. (1993). Geographic localization of knowledge spillovers as evidenced by patent citations. Quarterly Journal of Economics, 108, 557-598.

Ketokivi, MA, \& Schroeder, RG. (2004). Perceptual measures of performance: fact or fiction? Journal of Operations Management, 22(3), 247-264.

Koontz, TM, \& Thomas, CW. (2006). What do we know and need to know about the environmental outcomes of collaborative management? Public Administration Review, 66(6), 109-119.

Krugman, P. (1991). Geography and trade. Cambridge: MIT Press.

Landry, R, \& Nabil, A. (1998). The impact of transaction costs on the institutional structuration of collaborative academic research. Research Policy, 27(9), 901-913.

Landry, R, Traore, N, \& Godin, B. (1996). An econometric analysis of the effect of collaboration on academic research productivity. Higher Education, 32(3), 283-301.

Lee, S, \& Bozeman, B. (2005). The impact of research collaboration on scientific productivity. Social Studies of Science, 35(5), 673-702.

Lundvall, BA. (1992). National systems of innovations. Towards a theory of innovation and interactive learning. London: Pinter.

Maggioni, MA, Uberti, TE. (2007) Interregional knowledge flows in Europe: an econometric analysis. In: Frenken, K. (ed.) Applied Evolutionary Economics and Economic Geography, (pp. 230-255). Edward Elgar Publishing, Cheltenham.

MIT. (2002). Building scientific networks for effective innovation. MIT Sloan Management Review, 43(3), 14-14.

Murray, F. (2002). Innovation as co-evolution of scientific and technological networks: exploring tissue engineering. Research Policy, 31(8-9), 1389-1403.

Nelson, RR. (2001). Observations on the post-Bayh-Dole rise of patenting at American universities. The Journal of Technology Transfer, 26(1), 13-19.

Philbin, S. (2008). Measuring the performance of research collaborations. Measuring Business Excellence, 12(3), 16-23. $10.1108 / 13683040810900368$

Polt, W, Rammer, C, Schartinger, D, Gassler, H, \& Schibany, A. (2001). Benchmarking industry-science relations in Europethe role of framework conditions. EU Project (DG Enterprise): Brussels.

Rigby, J, \& Edler, J. (2005). Peering inside research networks: Some observations on the effect of the intensity of collaboration on the variability of research quality. Research Policy, 34(6), 784-794. 
Shelton, R. (2008). Relations between national research investment and publication output: Application to an American Paradox. Scientometrics, 74(2), 191-205.

Technopolis. (2004). Review of COST domains in the chemical and physical sciences. Brighton: Technopolis.

TNS Opinion and Social. (2005). Europeans, science and technology. Special Eurobarometer 224/Wave 63.1. Brussels, Belgium: European Commission.

van Zee, A, \& Engel, P. (2004). Networking for learning: what can participants do? Zeist: Interchurch Organisation for Development Cooperation. (ICCO); Maastricht: European Centre for Development Policy Management.

10.1186/2192-5372-3-6

Cite this article as: Rakhmatullin and Brennan: Facilitating innovation in European research area through pre-competitive EU-funded COST Actions. Journal of Innovation and Entrepreneurship 2014, 3:6

Submit your manuscript to a SpringerOpen ${ }^{\circ}$ journal and benefit from:

- Convenient online submission

- Rigorous peer review

- Immediate publication on acceptance

- Open access: articles freely available online

- High visibility within the field

- Retaining the copyright to your article

Submit your next manuscript at $\boldsymbol{~ s p r i n g e r o p e n . c o m ~}$ 